\title{
Crystallographic oxide phase identification of char deposits obtained from space shuttle Columbia window debris
}

\author{
J. D. Olivas ${ }^{1}$, M. C. Wright ${ }^{2}$, R. Christoffersen ${ }^{3}$, D. M. Cone ${ }^{4}$ and S. J. McDanels ${ }^{2}$ \\ ${ }^{I}$ National Aeronautics and Space Administration, Johnson Space Center, Houston, TX \\ ${ }^{2}$ National Aeronautics and Space Administration, Kennedy Space Center, FL \\ ${ }^{3}$ Science Applications International Corporation, Johnson Space Center, Houston, TX \\ ${ }^{4}$ National Aeronautics and Space Administration, White Sands Test Facility, NM
}

\section{$\underline{\text { Keywords }}$}

Transmission Electron Microscopy (TEM); Combustion; Titanium; Crystallization

\begin{abstract}
$\underline{\text { Abstract: }}$
Analyzing the remains of Space Shuttle Columbia has proven technically beneficial years after the vehicle breakup. This investigation focused on charred deposits on fragments of Columbia overhead windowpanes. Results were unexpected relative to the engineering understanding of material performance in a reentry environment. The TEM analysis demonstrated that the oxides of aluminum and titanium mixed with silicon oxides to preserve a history of thermal conditions to which portions of the vehicle were exposed. The presence of Ti during the beginning of the deposition process, along with the thermodynamic phase precipitation upon cool down, indicate that temperatures well above the Ti melt point were experienced. The stratified observations implied that additional exothermic reaction, expectedly metal combustion of a Ti structure, had to be present for oxide formation. Results are significant for aerospace vehicles where thermal protection system (TPS) breaches cause substructures to be in direct path with the reentry plasma.
\end{abstract}




\section{Introduction}

Evaluation of debris collected from the Space Shuttle Columbia accident continues years after the root cause analysis investigation was concluded by the Columbia Accident Investigation Board $[1,2]$. Present investigations are being conducted to better understand the effect of the plasma environment on orbiter structural and sub-structural materials which are not part of the thermal protection system (TPS) and, as such, are not typically expected to encounter reentry environments.

The relevance of these material investigations can be appreciated in cases where the primary thermal protection system has been compromised or is suspected to be compromised. During the history of the United States space program, compromises to the TPS have been documented for every space shuttle mission - 126 flights at this writing [3]. While all but one case did not result in loss of vehicle, the effect of entry conditions to regions of the substructure where compromised TPS was present has had limited study. In the post-Columbia era, an additional on-orbit TPS inspection has been conducted on every space shuttle launched and these on-orbit inspections revealed compromises to the TPS. While the vast majority of the TPS surfaces have been unaffected and any resultant effects inconsequential to TPS performance, two of six missions, STS-114 and STS-117, have required some level of reconfiguration or repair due to uncertainties in entry heating conditions/environments on the substructure [3]. Even during the pre-shuttle era, the Mercury-Atlas 6 (MA-6) mission experienced a TPS-suspect condition when the vehicle operator, John Glenn, relayed observations of the appearance of "fireflies" out the window which were attributed to material liberation from the TPS, whose overall integrity was then considered suspect [4].

A better understanding of how TPS substructural materials behave and respond under reentry environments can provide engineers with additional insight into the specifics of vehicle 
degradation when TPS is compromised. Ideally, a structure that experiences a prolonged degradation may provide the vehicle inhabitants with more time, and options, to either pass through regions of deleterious environmental effects, or allow for alternative repair measures to be performed. Using materials obtained from the orbiter structure and substructure exposed during the Columbia accident, the present investigation focuses on the details of phase transformation of some of these materials systems in an effort to identify several items. First, what unique characteristics, if any, are present in the remnant materials that could be uniquely resultant of the entry environment. Second, using those findings, what thermodynamic relationships could be correlated between the environment and the vehicle's thermodynamic history. Lastly, does the present engineering body of knowledge allow for safe and effective design, analysis and building of present and future spacecraft if the TPS is breached and substructural materials are exposed.

\section{Conditions for Material Deposition}

Perhaps the most dramatic, and recent, consequence of compromised TPS was seen during the reentry of Columbia on February 1, 2003. The breakup occurred when its velocity was in excess of Mach 18, at an altitude of over 200,000 $\mathrm{ft}(60,960 \mathrm{~m})$. The resultant debris experienced temperatures in excess of $1750^{\circ} \mathrm{C}$ [5]. While this was a direct consequence of a breach in the reinforced carbon-carbon (RCC) panel on the left wing leading edge, the substructure was exposed to ionized environments for which they were never designed. A recent investigation of the forward fuselage and crew compartment structures included examination of deposits found on the fused silica thermal panes of the overhead crew module windows 7 and 8 [6].

Orbiter overhead windows consist of three distinct panes of varying thickness: a thermally tempered aluminosilicate pressure pane, a redundant fused silica pane, and a thermal fused silica pane. Attached to the forward fuselage, the thermal pane provides thermal protection for the 
pressure and redundant panes while allowing crew visibility from within the crew module. In order to better understand the nature of the progression of the forward fuselage breakup, it was reasoned that the windows, unable to withstand structural distortions, would be indicative of the environmental conditions surrounding the corresponding structures prior to, and during, vehicle disintegration, and were therefore selected for analysis.

Using well-established microscopic and spectroscopic techniques, details emerged regarding the manner in which the charred deposited layer formed on top of the exposed glass during vehicle break-up in the plasma environment. Given the conditions surrounding the layer formation and materials from the surrounding regions, it was reasoned that the terrestrial technical field that would best serve as an experimental analogy was that of the thermal plasma spray coating deposition process. Studies on thermal plasma spray coatings have used various methodologies such as transmission electron microscopy (TEM) and X-ray diffraction (XRD) to characterize coating formation and morphology on glass substrates [7-13]. The thermal plasma spray process is one were the coating is a result of metallic and oxide powder particles injected into a plasma jet which are melted and propelled onto a prepared substrate, spreading and solidifying upon contact. Adhesion of the sprayed "splats" onto substrate material is controlled by the structure and properties of each material [8]. Due to the nature of the orbiter window substrate and the materials deposited, the same methodology proved useful in generating information about the sequence of events and structural material behavior during vehicle break-up.

\section{Experimental Procedure}

Cross-sectional samples of the window were prepared using typical materiallography techniques: mounting the areas of interest in a phenolic resin; grinding; polishing with diamond suspension media; and chemically etching. As seen in Figure 1, the char layer deposited non-uniformly on the glass, forming delineated layers of varying reflectivity, with acicular and nodular 
morphologies. A cross-sectional sample of the deposited char layer was prepared for TEM analysis using an FEI 200 TEM focused ion beam (FIB) with $30 \mathrm{kV}$ Ga liquid metal ion source. An in-situ FIB lift-out method was used to create a $1000 \AA$ thick sample for TEM evaluation. Platinum was deposited on the region of interest prior to FIB work to protect the surface from ion beam damage. The ion beam was used to mill out craters around the area of interest, and then mill the sample to a desired thickness. Chemical and crystallographic analysis of the specimen were performed with an FEI Tecnai F30 TEM containing a $300 \mathrm{kV}$ field emission source and equipped with scanning transmission electron microscopy (STEM) capability; a JEOL 2500SE FE STEM, high angle annular dark field spectroscopy (HAADF); and X-ray energy dispersive spectroscopy (EDS).

\section{Results and Discussion}

\subsection{Char layer general structure}

To fully characterize the species observed on the orbiter overhead window char layer, the 27.5 $\mu \mathrm{m}$ long by $8 \mu \mathrm{m}$ wide FIB sample, shown in Figure 2, was divided into four distinct regions based on morphology and chemical constituents: the glass substrate; an "inner layer" with densely packed equidimensional grains; an "outer layer" with isolated elongate grains; and a "porous layer" with nondescript grain morphology. The bright linear indication observed on the glass side was determined to be an artifact as a result of sample preparation. By contrast, the darker band adjacent to the char layer/glass interface, and approximately $1 \mu \mathrm{m}$ in thickness, was determined to be part of a continuous amorphous aluminosilicate glass matrix that surrounded the grains throughout the sample. The Si in this glassy matrix likely originated from the orbiter TPS components in close proximity to the windows since many of these components are silicon-rich materials. It was determined that devitrification of the glass did not take place because char layer elements were not detected below the substrate interface, indicating that no appreciable migration or mixing had occurred at the interface. Rather, the char layer appeared to be purely 
mechanically adhered to the orbiter glass. In terms of plasma sprayed coatings, this mechanical adhesion occurs when surface pits and grooves of a rough substrate are filled with spreading molten material under impact pressure [14-16]. While no detectable levels of such surface roughness was observed on the glass, it was apparent that the surface finish was adequate to provide for mechanical adhesion. The darker band, or "stand-off", was a crystal-free sub-layer of the "inner layer", thought to be an artifact of the random growth positioning of the equidimensional grains.

\subsection{Char layer-Inner layer phase identification}

Using Selected Area Electron Diffraction (SAED), the grains within the inner layer were identified as titanium dioxide $\left(\mathrm{TiO}_{2}\right.$, rutile). As seen in Figure 3, these crystals were equidimensional near the glass substrate interface; occurred in polycrystalline clusters as well as isolated islands; and were surrounded by the aluminosilicate glass matrix. Several crystals were subhedral in nature. Morphologies ranged from equidimensional near the substrate to irregular/elongate morphologies further from the interface with the glass. The lack of faceted grains implied the presence of significant undercooling after deposition which, in turn, inhibited the subhedral crystals from continuing growth. Kharas et al. observed similar morphologies of their plasma sprayed coating: a $100 \mathrm{~nm}$ thick chill zone made up of fine equiaxed grains near the splat boundary interface. The rapidly solidified chill zone of the coatings was observed on areas of good substrate contact, while areas of poor contact where heat transfer is slower exhibited larger grains [7]. Crystals within the inner layer occurred in polycrystalline clusters with contacting crystal-to-crystal grain boundaries near the substrate interface. Grain sizes in the inner layer varied from $300 \mathrm{~nm}$ to $1.8 \mu \mathrm{m}$. Within this region, an aluminum-rich phase was also observed intergranular to $\mathrm{TiO}_{2}$ grains; however, these only occurred at triple point junctions and did not exist as an isolated phase. About $5 \mu \mathrm{m}$ from the interface, the $\mathrm{TiO}_{2}$ crystals occurred in a more isolated, irregular and elongated structure within the aluminosilicate matrix. 


\subsection{Char layer-Outer layer phase identification}

In addition to predominantly acicular $\mathrm{TiO}_{2}$ grains, a crystalline aluminosilicate phase $\left(\mathrm{Al}_{4+2 x} \mathrm{Si}_{2-}\right.$ ${ }_{2 \mathrm{X}} \mathrm{O}_{10-\mathrm{x}}$, mullite) formed in the outer layer, about $11 \mu \mathrm{m}$ from the glass substrate interface. Within this region, these elongate grains measured $500 \mathrm{~nm}$ to $1 \mu \mathrm{m}$ traverse to the long axis of the crystal, and $750 \mathrm{~nm}$ to $3.5 \mu \mathrm{m}$ along the long axis. On average, these grains exhibited an aspect ratio of $3: 1$. Although more structurally complex than the inner layer, the outer layer appeared more homogeneous. In addition to the elongated phases, various mullite grains were observed as exhibiting a skeletal morphology. As with the inner layer, this was reasoned to be a result of rapid crystallization, in this case for the mullite phase shown in Figure 4 precipitating from the silicate melt. During the solidification of the char, the mullite crystals acted as heterogeneous nucleation sites for small titanium-oxide crystals that resulted from local depletion of aluminum and enrichment of titanium in the melt area adjacent to the mullite. Crystal growth arresting was also indicative of large undercooling.

\subsection{Char layer-Porous layer phase identification}

The last layer to deposit on the orbiter windows, the porous layer, was identified as having chemical composition indicative of a 2000-series aluminum component. Irregular in thickness, the porous layer was reasoned to have come from an $\mathrm{Al}$ alloy dispersed in the form of molten or semi-molten particles that partially cooled and/or oxidized prior to deposition. These features are noted in Figure 5.

\subsection{Char layer phase formations}

The compositional variations of the glass matrix in both the inner and outer layers were systematically studied using quantitative EDS analyses. Locations of the STEM raster analysis points are shown in Figure 6. The objectives of this effort were to: 1) gain insight into chemical 
compositional variations and proportions of the source materials during deposition, and 2) allow interpretation of the sample phase assemblages and crystallization history in terms of the $\mathrm{Al}_{2} \mathrm{O}_{3}$ $\mathrm{SiO}_{2}-\mathrm{TiO}_{2}$ phase diagram. Compositions from the outer layer and inner layer were plotted, and although the char layer contained appreciable amounts of $\mathrm{Ca}$ and $\mathrm{Fe}$ in addition to $\mathrm{Si}, \mathrm{Al}$ and $\mathrm{Ti}$, these elements were excluded from the analysis.

Despite the fact that they had significantly different phase assemblages with different crystallization histories, the results demonstrated significant overlap in glass compositions between the inner and outer layers. This suggests that their compositions may reflect convergent crystallization paths within the $\mathrm{Al}_{2} \mathrm{O}_{3}-\mathrm{SiO}_{2}-\mathrm{TiO}_{2}$ system. As demonstrated in Figure 7, with crystallization following along a mullite- $\mathrm{TiO}_{2}$ cotectic in the case of the outer layer, and along a $\mathrm{TiO}_{2}$ monotectic for the inner layer, the char layer composition was plotted and further studied.

The temperatures at which the inner and outer layer phase assemblages started to crystallize, and the temperatures at which they stopped crystallizing, were estimated using a phase diagram for the $\mathrm{Al}_{2} \mathrm{O}_{3}-\mathrm{SiO}_{2}-\mathrm{TiO}_{2}$ system as well as estimates for the bulk composition of the inner and outer layers. Reference to the phase diagram in Figure 8 indicates that crystallization happened in the range of $1500-1700^{\circ} \mathrm{C}$. Given that the inner and outer layers appear to have been completely molten at some point, they were most likely above $1700^{\circ} \mathrm{C}$ prior to being deposited onto the glass substrate.

It is acknowledged that in the aforementioned ternary phase diagram temperature inferences, the present reconstruction of the thermodynamics of the char layer appears to be missing the tialite phase $\left(\mathrm{Al}_{2} \mathrm{TiO}_{5}\right)$ that the diagram predicts should have been present [17]. This may suggest that crystallization within the char layer may have been affected by non-equilibrium factors or that the phase diagram used for the present study is insufficient, considering the $\mathrm{Ca}$ and $\mathrm{Fe}$ impurities 
identified. Furthermore, estimates of the bulk compositions were based on relative volumetric percentages of the rutile and mullite phases. These were acknowledged to be rough estimates.

\subsection{Char layer assemblage}

A three-zone (inner, outer, porous) char layer was only observed on the exterior of the orbiter Columbia overhead windows 7 and 8 thermal panes; this type of char layer was not evident on the pressure panes or any of the other orbiter windows, leading to the conclusion that the overhead windows were intact during the deposition process. Although the majority of the metallic structural materials in the vicinity of the overhead windows were 2000 -series Al, a Ti-based source was responsible for the initial deposition events during a phase in flight when the aerostructure was in a less dynamic state relative to the velocity vector. Orbiter structural members in close proximity to the windows and composed of a titanium alloy are the Ti- $6 \%$ aluminum- $4 \%$ vanadium (Ti-6-4) $\mathrm{X}_{0} 586$ payload bay bulkhead latch rollers. Recovered from the debris, these rollers exhibited significant thermal erosion. Additionally, the structure which supported the roller components was largely made of $2024 \mathrm{Al}$. The structural components not made of Ti-6-4 but adjacent to the rollers appeared to have less amounts of thermal erosion. Finally, regions further away from the rollers, but presumably exposed to near identical thermal conditions, showed minimal signs of thermal degradation, and even included the presence of the Koropon primer.

The amorphous aluminosilicate "stand-off" region observed at the char deposit substrate interface prior to crystal formation was likely due to rapid solidification. This region acted as an insulating barrier, decreasing heat transfer and allowing $\mathrm{TiO}_{2}$ phase precipitation. In their study of $\mathrm{Al}_{2} \mathrm{O}_{3} / \mathrm{ZrSiO}_{4}$ plasma sprayed coatings, $\mathrm{Li}$ et al. found similar amorphous phases coexisting with equiaxed crystals, resulting from the amorphous material acting as a barrier to heat flow [19]. It is expected that mechanical adhesion occurred as surface disparities on the glass substrate filled 
with spreading molten debris under impact pressure. To that effect, the subhedral equidimensional morphology of the $\mathrm{TiO}_{2}$ crystals within the inner layer near the glass substrate implied deposition of molten $\mathrm{TiO}_{2}$ rather than solidified $\mathrm{TiO}_{2}$ particles. Subsequent epitaxial growth in the aluminosilicate glass matrix indicated that the subhedral $\mathrm{TiO}_{2}$ solidified due to rapid undercooling, which in turn provided an insulating layer curtailing the undercooling effect in the outer layer. Undercooling within this region was still substantial; however, conditions to support epitaxial grain growth in the solidifying glass matrix were maintained. Heterogeneous and continuous outer layer structures denoted that the deposited material was continuously supplied to the orbiter windows and the windows were likely not in motion relative to the source during the deposition process.

Noting its indiscernible morphology, it is expected that the porous Al layer was deposited during a substantially more dynamic episode than the inner and outer layers. This final layer was a result of the dynamic process when the glass and its structural frame possessed a high relative motion with respect to the deposition source. The porous layer was irregular in thickness and contained distinct particles of other oxidized metal systems. The 2000 -series $\mathrm{Al}$ alloy was deposited in the form of molten or semi-molten particles that partially cooled and/or oxidized prior to impacting the glass substrate. It was then inferred that the layer was formed from one or a combination of the following scenarios: having the potential source a significant distance from the window; passing of the substrate through a vapor trail of some other portion of debris; or having the deposition source violently tumbling along with the glass substrate. It is conceivable that all three processes were occurring, however, to what degree each was responsible is not possible to discern with the data obtained.

\subsection{Combustion of metals in reentry environments}


$\mathrm{TiO}_{2}$ crystal formation in the inner and outer layers of the char deposit indicated that the Ti-6-4 metallic components may have undergone a thermal erosion process which would have been energetic enough to result in a near 100\% conversion efficiency of metallic Ti to oxidized Ti. Additionally, sufficient thermal inertia would have had to been present to allow for the elemental mobility and crystal growth observed of the oxides. Other than an undefined, hypothetical aerothermal process, such as shock-shock interaction, metallic combustion appeared to be a likely candidate to provide for the thermal conditions necessary to explain the observations. A comprehensive literature search on the subject of Ti combustion experiments in various environments indicate that under certain hypersonic conditions, Ti may be extremely reactive with the environment to result in both ignition and combustion [20]. For completeness, it should be recognized that these observation were based on anecdotal presentation by researchers as opposed to test results stemming from direct testing.

Although inherently a very complex interaction of a large number of interrelated chemical and physical processes, metal combustion can be viewed fundamentally from the standpoint of the kinetics and thermodynamics of metal-oxygen reactions along with the various mechanisms of oxidation, ignition and combustion. From this perspective, it is important to note that the only fundamental difference between metal oxidation and combustion is the extent of the reaction: "passive" metallic oxidation is the same as "active" metallic combustion, albeit at a very slow rate - one that allows the thermal energy derived from the exothermic heats of formation to be effectively dissipated to the surroundings, thus preventing a temperature rise. Ignition is a thermal instability that occurs when the heat generation rate from the oxidation reaction exceeds the capacity of the surrounding metal to dissipate it, the prerequisite condition for a thermal runaway. The quasi-steady state combustion that may follow ignition is a new equilibrium state in which the rate of heat generation is governed by a different set of rates and mechanisms but that maintains a close balance to the heat lost to the surroundings. Dynamic combustion is a 
condition typically associated with a dynamic environment involving rapidly changing mass and heat transfer rates, often of an unpredictable nature and involving aggressive propagation and material consumption.

Several distinct characteristics are exhibited by the process of metal combustion which are largely the direct result of the thermo-chemical stability of the resulting metal oxides. The stability of the oxide compound implies a large release of thermal energy during combustion, in that the heats of formation are correspondingly large, and that the products of combustion will be present in the reaction zone as condensed solid or liquid phases. Consequently, one characteristic of metal combustion is that very high-localized temperatures can be achieved. This is thought to be limited by the dissociation pressure of the metal oxide but often achieves temperatures in excess of $2700^{\circ} \mathrm{C}[21]$. The presence of the oxide reaction products in the combustion zone can also strongly influence the ability of a metal fire to propagate. Given the refractory nature of the metal oxides, a significant portion of the exothermic reaction energy will exist in the enthalpy of the reaction products. Molten oxide products that collect on the surface of a combusting metal can contribute an additional heat content that aids in melting metal adjacent to the reaction zone. Should this molten mixture of metal and metal oxide with inherently high heat content be exposed to centrifugal or aerodynamic forces, it can be concluded that the combustion reaction could readily be spread to other nearby structural components.

In addition to the very high radiant emission of combusting metals, which is attributed temperatures in excess of $2700^{\circ} \mathrm{C}$ in the reaction zone and large concentration of condensed oxide particles that lend the metal flames a high emissivity, another set of characteristics that is less well understood are the violent fragmentation and explosions that often accompany metal combustion. Fine powders of metals like zirconium $(\mathrm{Zr})$, tantalum $(\mathrm{Ta}), \mathrm{Ti}$, and $\mathrm{Al}$ have been observed to explode shortly after being ignited in an oxidizing atmosphere, a condition apparently 
related to the high reactive surface-to-volume ratio of the powdered form. Identical conditions with the same metals in bulk form do not exhibit violent explosions, but tend rather to "boil" vigorously while ejecting a continuous spray of small molten droplets, which can often themselves explode or continue to burn until forming a still molten yet completely oxidized metallic oxide mass [22]. In the case of the Columbia overhead window deposits, it is expected that the bulk Ti-6-4 roller material underwent the latter. Although the exact environmental conditions surrounding the exposure of the rollers were not known, the crystallographic structure of the char layer appeared to be more consistent with what one might expect from an exothermic conversion of metallic Ti to an oxidized Ti during combustion.

\section{Conclusion}

Microscopic evaluation of a char layer deposited during reentry breakup of orbiter vehicle Columbia revealed an unexpected sequence and structure of deposited materials. The char layer entailed an aluminosilicate glass matrix with three distinct layers: an inner layer of equidimensional subhedral $\mathrm{TiO}_{2}$ crystals, leading to an outer layer of elongate $\mathrm{TiO}_{2}$ and acicular mullite crystals, and finally a metallic aluminum porous layer. The deposition process was less dynamic in nature at the beginning stages of deposition, leading to more dynamic deposition of the top most porous layer. It was hypothesized that materials deposited on windows 7 and 8 were the result of combustion of a Ti-6Al-4V source in addition to interaction with surrounding $\mathrm{Al}$ and Si components. Considering the lower melting temperature of Al alloys compared to Ti-based alloys, finding Ti oxide formation at the beginning stages of deposition was unexpected and is attributed to the conversion of metallic $\mathrm{Ti}$ from the Ti-6Al-4V rollers to $\mathrm{TiO}_{2}$ due to combustion.

Depending on flight Mach number and mission profile, vehicles that fly at hypersonic speeds may be exposed to severe aero-thermodynamic environments [23]. Because various Ti-based alloys and composites are among the top candidate advanced materials used for reentry environments 
[24-25], it is imperative that combustibility and ignition of aerospace metals be appreciated. Further studies on the combustion behavior of $\mathrm{Ti}$ in a plasma environment are needed to adequately verify Ti usage for aerodynamic substructural members that may be exposed to a reentry environment after a breach in the TPS.

In more general terms, the aerospace design community cannot neglect the potential for environmental reactivity of substructural materials given our history of compromised TPS if the desire is to have a well-predicted and expected degradation. This understanding is tantamount to providing spacecraft occupants with the greatest opportunity to safely pass through the regions of concern, into one where the deleterious effects are no longer a concern.

\section{$\underline{\text { Acknowledgments }}$}

The authors wish to thank the following for their contributions: Pam Melroy, Glenn Morgan, Lou Hulse, Leslie Schachel and Brian Mayeux of the NASA Johnson Space Center; Terryl Wallace of the NASA Langley Research Center; and Zia Rahman of the Advanced Materials Processing and Analysis Center at the University of Central Florida.

\section{$\underline{\text { References }}$}

1. Columbia Accident Investigation Board (CAIB), Report Volume 1, National Aeronautics and Space Administration, Washington, DC, August 2003.

2. R. Russell, “Space Shuttle Columbia Debris Loan Process: Examples of Microscopic Analysis", 2006 Microscopy and Microanalysis Conference, Chicago, IL.

3. “Orbiter Green Book," https://opo.nasa.gov/greenbook/, March 2009

4. J. O'Keefe, "Preliminary Report on the Results of the MA-6 Flight in the Field of Space Science", Appendix D of NASA-TM-108605, Results of the First United States Manned Orbital Space Flight, February 20, 1962 
5. B. Mayeaux, S. McDanels, et al, "Materials Analysis: A Key to Unlocking the Mystery of the Columbia Tragedy", Journal of Materials, February 2004.

6. J.D. Olivas, P. Melroy, et al, "OV-102 Thermal Pane Window Debris Analysis", part of Spacecraft Crew Survival Integration Investigation Report, NASA, 2008.

7. B. Kharas et al, Morphology and microstructure of thermal plasma sprayed silicon splats and coatings, Surface \& Coatings Technology 201 (2006) 1454-1463

8. T. Chraska and A King, Transmission electron microscopy study of rapid solidification of plasma sprayed zirconia - part II. Interfaces and subsequent splat solidification, Thin Solid Films 397 (2001) 40-48

9. H. Salimijazi, Study of solidification behavior and splat morphology of vacuum plasma sprayed Ti alloy by computational modeling and experimental results, Surface Coatings and Technology 201 (2007) 7924-7931

10. Sampath et al, Substrate temperature effects on splat formation, microstructure development and properties of plasma sprayed coatings Part I: Case study for partially stabilized zirconia, Materials Science and Engineering A 272 (1999) 181-188

11. Syed et al, Influence of substrate surface conditions on the plasma sprayed ceramic and metallic particles flattening, Surface Coatings \& Technology 200 (2005) 2317-2331

12. C. Kong et al, The microstructures of a thermally sprayed and heat treated Al-20 wt $\% \mathrm{Sn}$ 3 wt\% Si alloy, Materials Science and Engineering A 403 (2005) 205-214

13. H. Jin et al, Microstructural evolution of the rapidly-quenched $\mathrm{Fe}-\mathrm{Cr}-\mathrm{B}$ alloy thermal spray coatings, Materials Science and Engineering A 304-306 (2001) 1069-1074

14. J.D. Olivas, C. Mireles, E. Acosta, and E.V. Barrera, "Surface Characterization of Plasma Spray Metal Process Using X-ray Photoelectron Spectroscopy," Thin Solid Films, 299 (1997) 143 
15. J.D. Olivas and E.V. Barrera, "Surface Characterization of Various Plating and Coating Processes Using XPS,” AVS-International Conference on Metallurgical Coatings and Thin Films, San Diego, CA, April (1995)

16. J.D. Olivas, J. Sims, E. Acosta, and E.V. Barrera,, “An X-ray Photoelectron Spectroscopy (XPS) Study Various Coating Process for Aircraft and Jet Engine Application," Surfair X-International Conference on Surface Treatments in the Aeronautical and Aerospace Industries, Cannes, France, June (1994)

17. Agamawi, Y.M. and White, J., Transactions of the British Ceramic Society, 51, 319, (1952), 293-325

18. Kim, I. and Lee, K. "Characterization of aluminum titanate-mullite ceramics synthesized by a semi solgel method” Journal of Ceramic Processing Research. Vol. 4, No. 4, pp. 202 209 (2003)

19. Y. Li, Microstructure and composition analysis in plasma sprayed coatings of $\mathrm{Al}_{2} \mathrm{O}_{3} / \mathrm{ZrSiO}_{4}$ mixtures, Surface Coatings \& Technology 150 (2002) 125-132

20. Rochelle, W. C., "Survey of Titanium Testing at NASA, DOE, and DOD Test Facilities," ESCG-4380-06-AFD-MEMO-0011, April 20, 2006.

21. Glassman, I., "Metal Combustion Process". American Rocket Society, $14^{\text {th }}$ Annual Meeting, (1959) 938-959

22. Clark, A.F, "The Combustion of Bulk Titanium in Oxygen," $15^{\text {th }}$ International Symposium on Combustion, The Combustion Institute (1975).

23. J. Bertin \& R. Cummings, "Fifty years of hypersonics: where we've been, where we're going", Progress in Aerospace Sciences 39 (2003) 511-536

24. G. Orton, "A hypersonic cruiser concept for the $21^{\text {st }}$ century", SAE paper 985525 , September 1998

25. B. Behrens, “Technologies for thermal protection system applied on re-usable launcher", Acta Astronautica 55 (2004) 529-536 


\section{Figures}

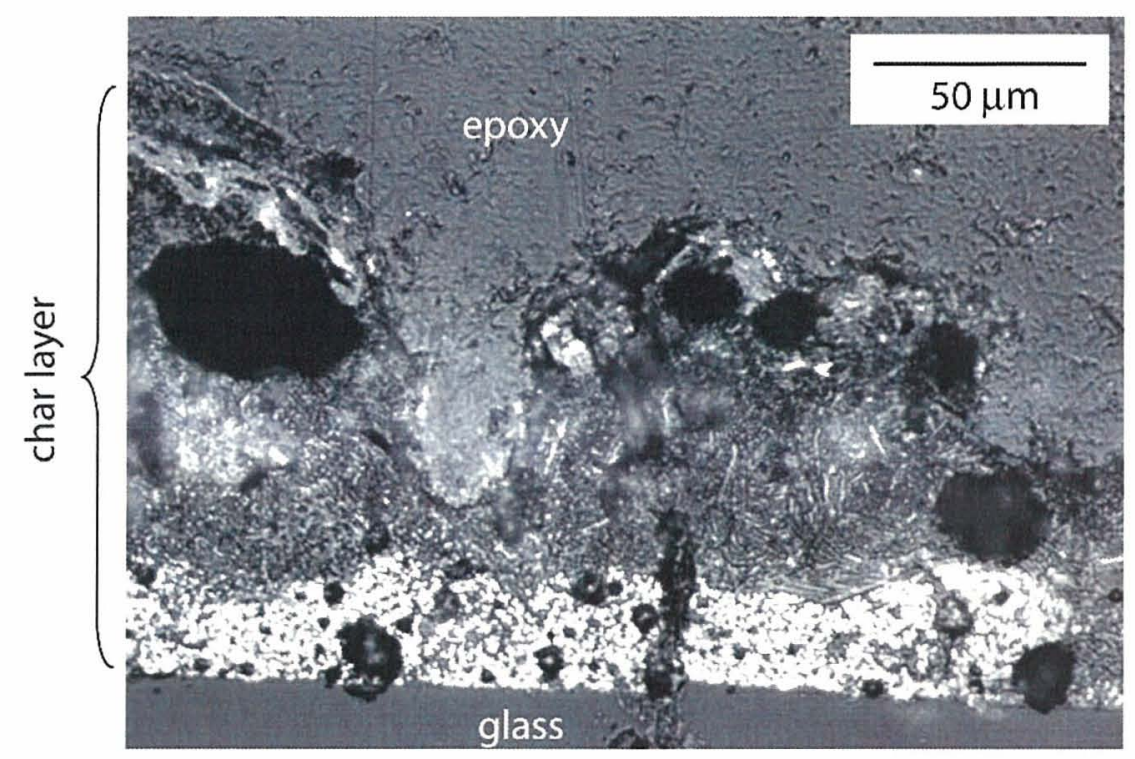

Figure 1. Optical microscopy image of a polished and etched window cross section.

(a)

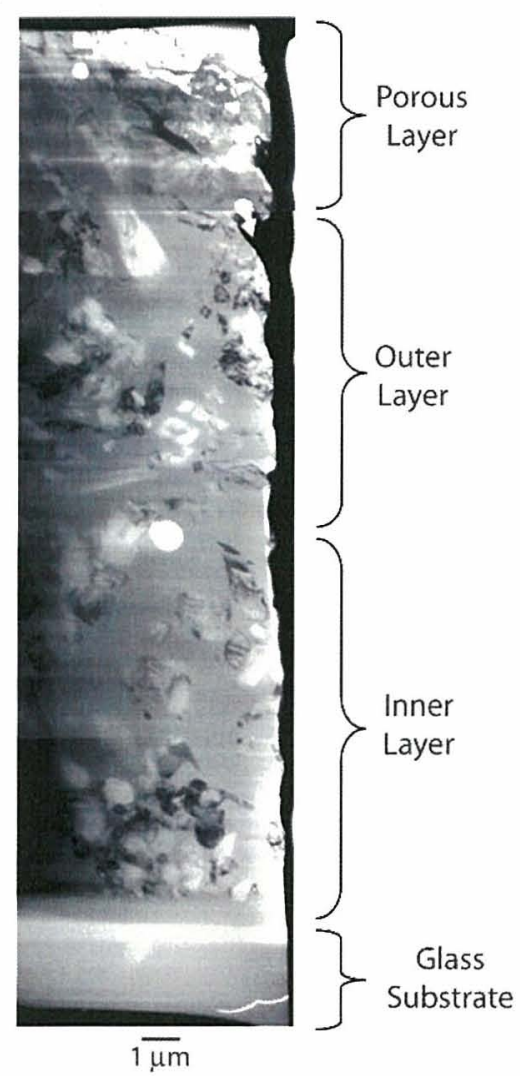

(b)

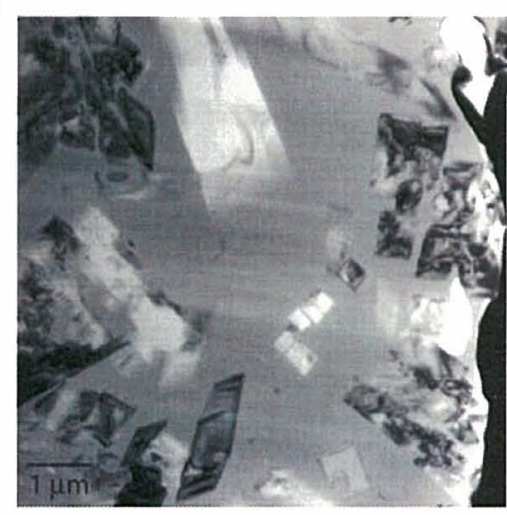

(c)

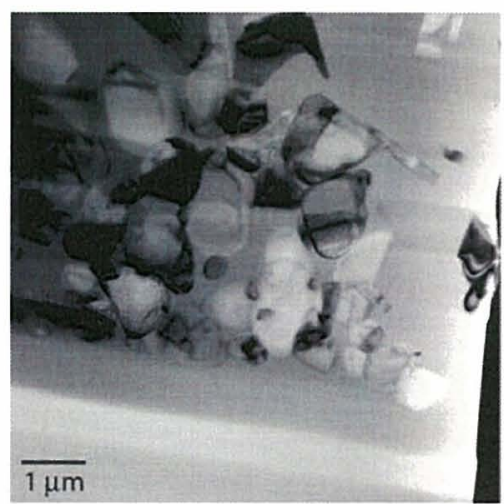

Figure 2. (a) Bright Field TEM images of the deposited char layer showing all layers deposited on the orbiter window glass substrate including the (b) outer and (c) inner layers. 


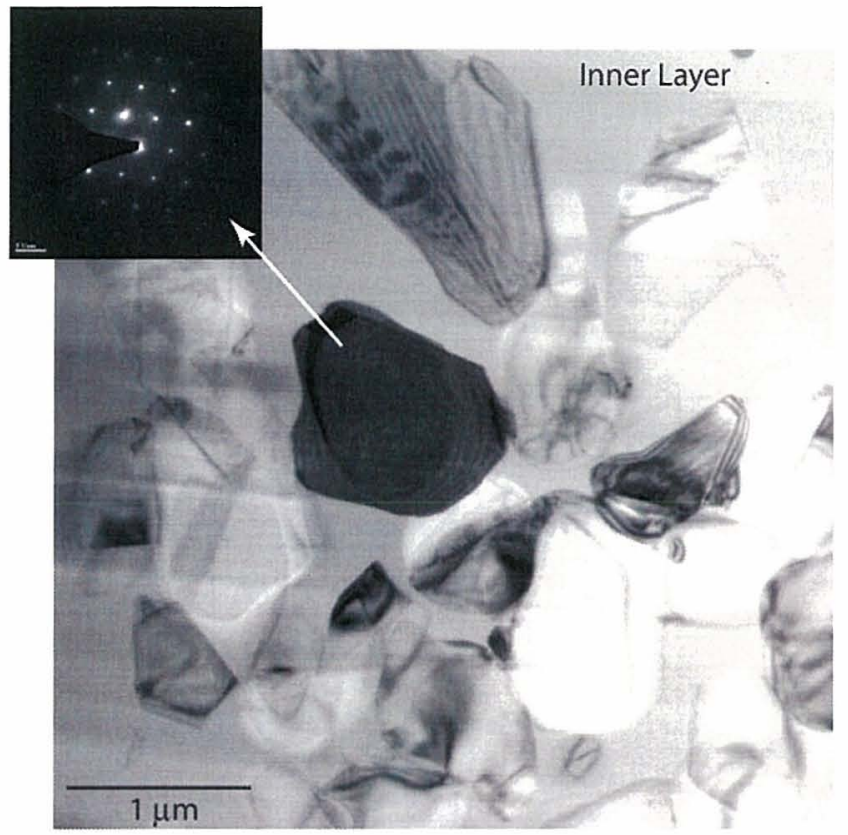

Figure 3. Bright Field TEM image of inner layer subhedral $\mathrm{TiO}_{2}$ crystals in aluminosilicate matrix and diffraction pattern of a representative crystal.

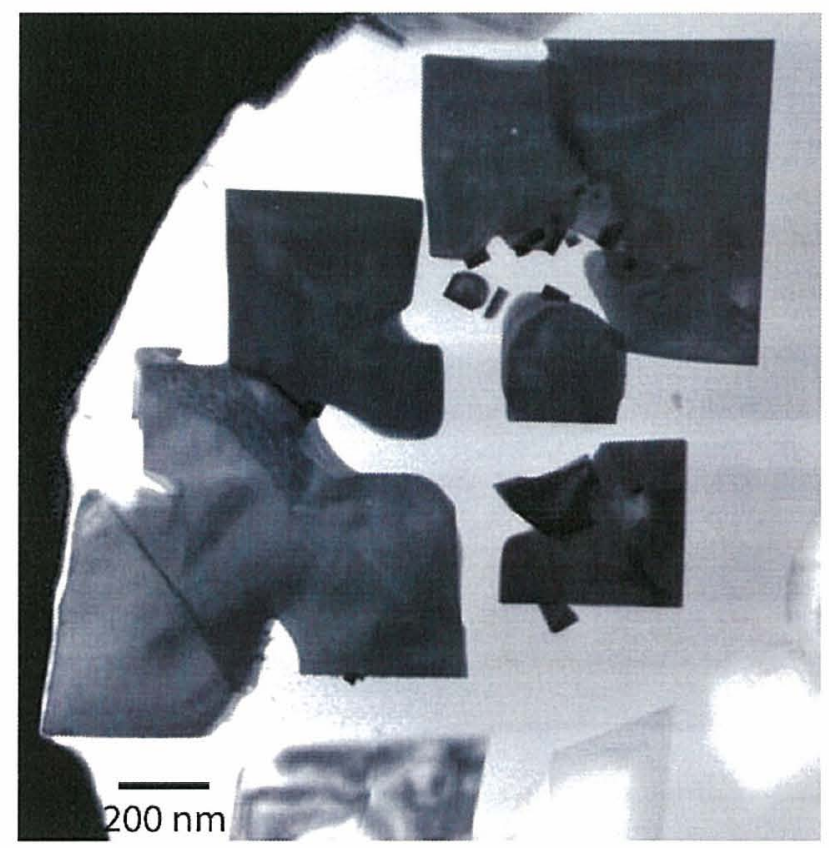

Figure 4. Bright Field TEM image of mullite crystals with a skeletal morphology, indicative of rapid crystallization from a silicate melt. 


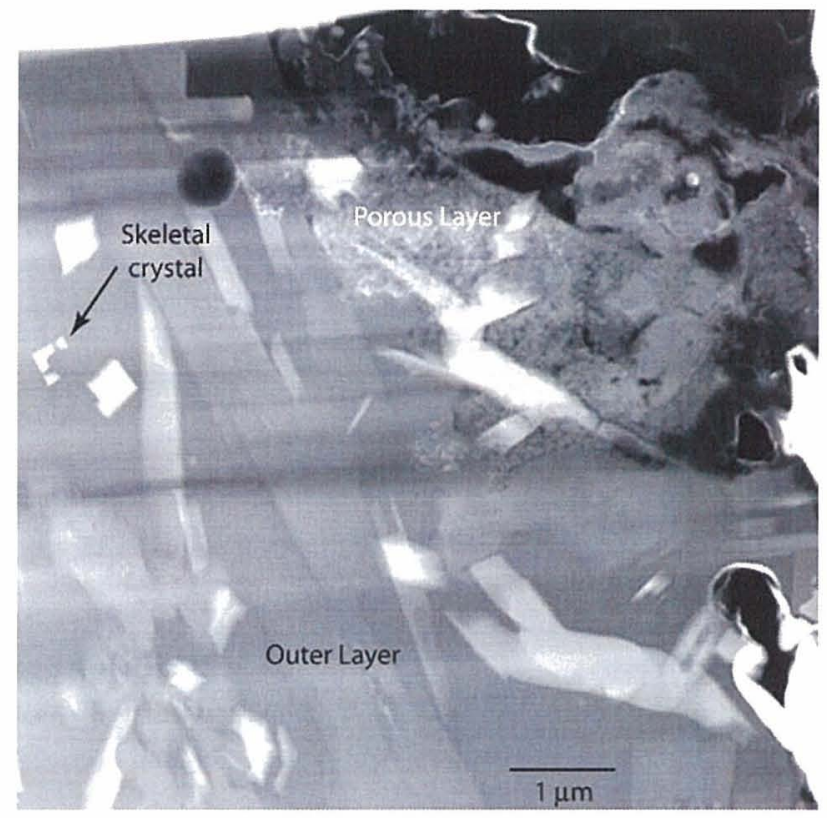

Figure 5. Dark Field STEM image of top porous aluminum layer of char deposit and portion of the outer layer. The porous layer is non-descript in grain morphology. 


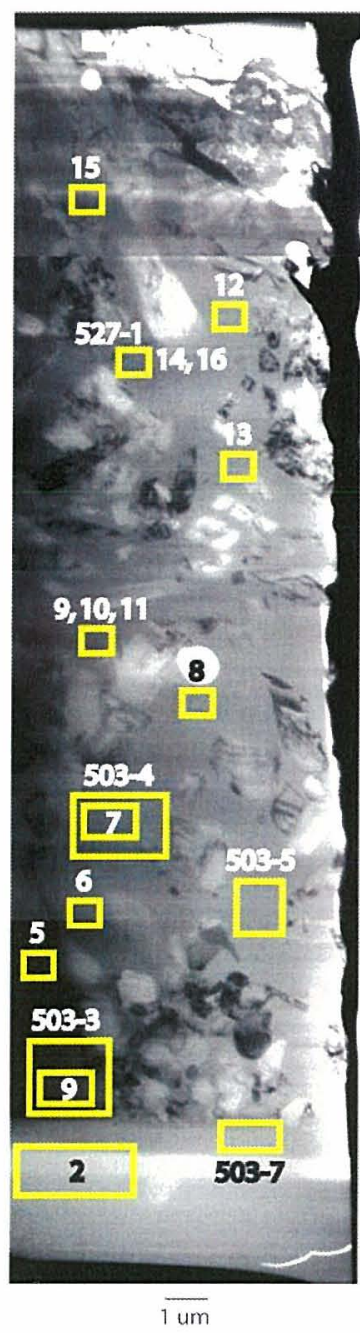

\begin{tabular}{|c|cccccc|}
\hline \multicolumn{7}{|c|}{ Wt. \% Elements } \\
\hline & Si & Al & Ca & Fe & Ti & O \\
\hline $\mathbf{2}$ & 46.07 & 0.62 & 0.02 & 0.11 & 0.06 & 53.12 \\
$\mathbf{5}$ & 27.14 & 13.5 & 3.69 & 1.93 & 5.28 & 48.47 \\
$\mathbf{6}$ & 27.03 & 13.72 & 3.68 & 1.98 & 5.12 & 48.46 \\
$\mathbf{7}$ & 25.97 & 14.37 & 3.8 & 2.26 & 5.43 & 48.17 \\
$\mathbf{8}$ & 25.6 & 15.01 & 3.96 & 2.53 & 4.85 & 48.06 \\
$\mathbf{9}$ & 23.92 & 14.68 & 4.79 & 3.56 & 5.89 & 47.17 \\
$\mathbf{1 0}$ & 23.34 & 14 & 4.72 & 3.36 & 7.61 & 46.97 \\
$\mathbf{1 1}$ & 22.96 & 13.7 & 4.6 & 3.36 & 8.52 & 46.84 \\
$\mathbf{1 2}$ & 26.48 & 12.21 & 4.82 & 4.32 & 4.79 & 47.39 \\
$\mathbf{1 3}$ & 25.51 & 12.51 & 4.22 & 3.8 & 6.59 & 47.37 \\
$\mathbf{1 4}$ & 24.73 & 12.6 & 4.91 & 4.28 & 6.54 & 46.94 \\
$\mathbf{1 5}$ & 26.7 & 15.09 & 2.82 & 2.9 & 4.01 & 48.48 \\
$\mathbf{1 6}$ & 26.1 & 13.62 & 3.96 & 3.34 & 5.15 & 47.83 \\
$\mathbf{5 0 3 - 3}$ & 32.52 & 11.56 & 3.15 & 1.56 & 1.31 & 49.91 \\
$\mathbf{5 0 3 - 4}$ & 26.05 & 14.29 & 3.77 & 2.26 & 5.44 & 48.18 \\
$\mathbf{5 0 3 - 5}$ & 26.62 & 14.09 & 3.62 & 1.99 & 5.28 & 48.4 \\
$\mathbf{5 0 3 - 7}$ & 35.08 & 7.42 & 1.9 & 0.83 & 4.33 & 50.45 \\
\hline
\end{tabular}

Figure 6. Dark Field STEM image of char deposit. Locations identified on the Figure correspond to EDS results located in the table. 

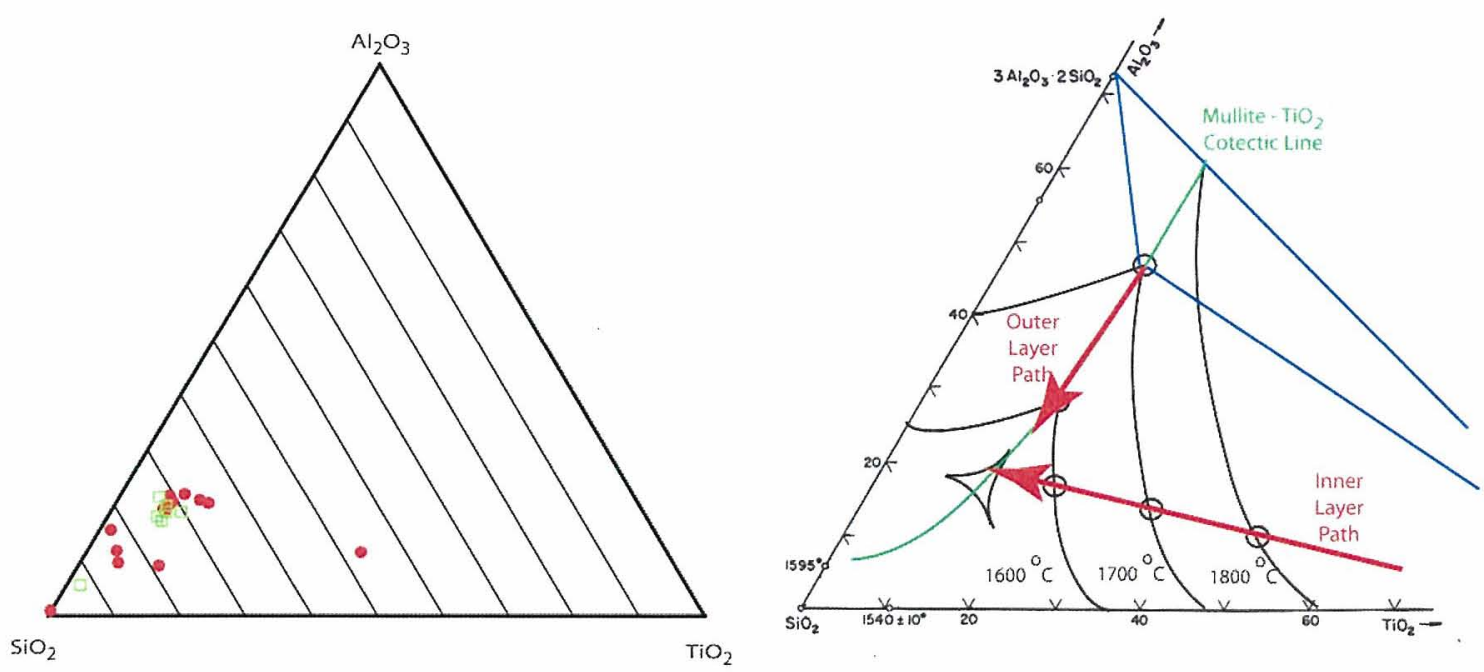

Figure 7. Composition data from Figure 6 plotted on a ternary phase diagram for $\mathrm{Al}_{2} \mathrm{O}_{3}-\mathrm{SiO}_{2}-$

$\mathrm{TiO}_{2}$ (left). Blow up of region where glass compositions of char layer maps onto highsilica region is plotted on phase diagram [16].

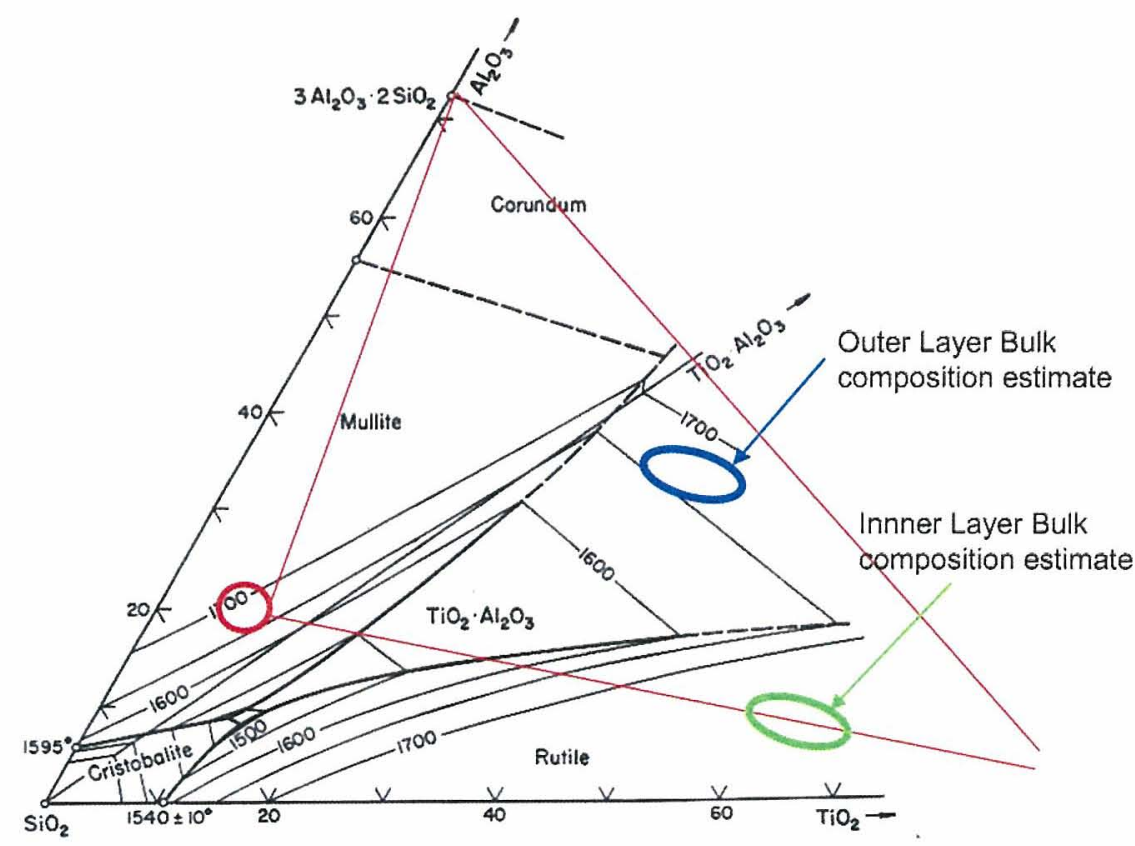

Figure 8. Ternary phase diagram for $\mathrm{Al}_{2} \mathrm{O}_{3}-\mathrm{SiO}_{2}-\mathrm{TiO}_{2}[16]$ 